\title{
Structural Analysis of Prion Proteins by Means of Drift Cell and Traveling Wave Ion Mobility Mass Spectrometry
}

\author{
Gillian R. Hilton, ${ }^{\mathrm{a}, *}$ Konstantinos Thalassinos, ${ }^{\mathrm{a}, *}$ Megan Grabenauer, ${ }^{\mathrm{b}}$ \\ Narinder Sanghera, ${ }^{a}$ Susan E. Slade, ${ }^{a}$ Thomas Wyttenbach, ${ }^{\text {b }}$ \\ Philip J. Robinson, ${ }^{a}$ Teresa J. T. Pinheiro, ${ }^{\text {a }}$ Michael T. Bowers, ${ }^{\text {b }}$ and \\ James H. Scrivens ${ }^{a}$ \\ ${ }^{a}$ Department of Biological Sciences, University of Warwick, Coventry, United Kingdom \\ ${ }^{\mathrm{b}}$ Department of Chemistry, University of California-Santa Barbara, Santa Barbara, California, USA
}

\begin{abstract}
The prion protein (PrP) is implicitly involved in the pathogenesis of transmissible spongiform encephalopathies (TSEs). The conversion of normal cellular $\operatorname{PrP}\left(\operatorname{PrP}^{\mathrm{C}}\right)$, a protein that is predominantly $\alpha$-helical, to a $\beta$-sheet-rich isoform $\left(\mathrm{PrP}^{\mathrm{Sc}}\right)$, which has a propensity to aggregate, is the key molecular event in prion diseases. During its short life span, $\mathrm{PrP}$ can experience two different $\mathrm{pH}$ environments; a mildly acidic environment, whilst cycling within the cell, and a neutral $\mathrm{pH}$ when it is glycosyl phosphatidylinositol (GPI)-anchored to the cell membrane. Ion mobility (IM) combined with mass spectrometry has been employed to differentiate between two conformational isoforms of recombinant Syrian hamster prion protein (SHaPrP). The recombinant proteins studied were $\alpha$-helical SHaPrP(90-231) and $\beta$-sheet-rich $\operatorname{SHaPrP}(90-231)$ at $\mathrm{pH} 5.5$ and $\mathrm{pH}$ 7.0. The recombinant proteins have the same nominal mass-to-charge ratio $(\mathrm{m} / \mathrm{z})$ but differ in their secondary and tertiary structures. A comparison of traveling-wave (T-Wave) ion mobility and drift cell ion mobility (DCIM) mass spectrometry estimated and absolute cross-sections showed an excellent agreement between the two techniques. The use of T-Wave ion mobility as a shape-selective separation technique enabled differentiation between the estimated cross-sections and arrival time distributions (ATDs) of $\alpha$-helical SHaPrP(90-231) and $\beta$-sheet-rich $\mathrm{SHaPrP}(90-231)$ at $\mathrm{pH}$ 5.5. No differences in cross-section or ATD profiles were observed between the protein isoforms at $\mathrm{pH}$ 7.0. The findings have potential implications for a new ante-mortem screening assay, in bodily fluids, for prion misfolding diseases such as TSEs. (J Am Soc Mass Spectrom 2010, 21, 845-854) (C) 2010 American Society for Mass Spectrometry
\end{abstract}

$\mathrm{T}$ Transmissible spongiform encephalopathies (TSEs), also known as prion diseases, are a class of fatal, infectious neurodegenerative diseases that can affect both humans and animals. Examples of prion diseases include bovine transmissible spongiform encephalopathy (BSE), chronic wasting disease (CWD) in deer, scrapie in sheep, and Creutzfeldt-Jakob disease (CJD) in humans [1]. The identity of the infectious agent in prion disease was first documented by Prusiner and coworkers [2] in 1982, who isolated a misfolded form of a native glycoprotein, PrP (product of the Prnp gene) and proposed this was the major constituent of the infectious prion particle. They proposed that these unprecedented infectious pathogens cause prion diseases by an entirely novel mechanism [3]. Although the precise molecular details of the mechanism are not

Address reprint requests to Professor J. H. Scrivens, Department of Biological Sciences, University of Warwick, Gibbet Hill Road, Coventry, CV4 7AL, UK. E-mail: j.h.scrivens@warwick.ac.uk

* These two authors contributed equally to this work. clearly known, it is thought that the key event in prion diseases is the conversion of the normal cellular form of the prion protein, $\left(\mathrm{PrP}^{\mathrm{C}}\right)$ to a pathogenic scrapie form $\left(\operatorname{PrP}^{\mathrm{Sc}}\right)$. Detailed biochemical analysis of $\operatorname{PrP}^{\mathrm{C}}$ and $\operatorname{PrP}^{\mathrm{Sc}}$ revealed major differences in the biochemical properties of both isoforms; $\mathrm{PrP}^{\mathrm{C}}$ is monomeric and readily degraded by proteases whilst $\mathrm{PrP}^{\mathrm{Sc}}$ has a high propensity to aggregate and is partially resistant to digestion with proteases. The failure to identify post-translational modifications to the protein molecule [4] led to the suggestion that the difference in the physical properties, of both isoforms, is a consequence of different conformations rather than chemical modifications. The Cterminal (amino acid residues 91-231) solution structure of $\operatorname{PrP}^{\mathrm{C}}$, in mouse, hamster and human $\operatorname{PrP}$, has been determined [5-7] and was found to consist of $\sim 47 \%$ $\alpha$-helices, while $\mathrm{PrP}^{\mathrm{Sc}}$ has a significantly higher percentage of $\beta$-sheet structure $(\sim 45 \%)$ [8].

TSEs came to prominence when an epidemic of BSE in the UK caused the death of many hundreds of cattle in the 1980s-1990s [9-11]. A new TSE, designated 
variant-CJD (v-CJD), appeared in humans and was linked to the consumption of BSE-infected material from cattle [12]. It has been observed that v-CJD can be iatrogenically transferred from human to human via the use of contaminated surgical equipment and by blood transfusion [13]. It is believed that many people in the UK could be asymptomatic carriers of the prion disease as the incubation period of $\mathrm{v}$-CJD can be upwards of 40 y [14]. Until recently, all known v-CJD patients were methionine homozygotes at codon 129 of the prion protein gene (PRNP). A case of preclinical $\mathrm{v}$-CJD in a patient that had received a blood transfusion from a carrier of v-CJD was reported in 2004 [15]. This patient was heterozygous at codon 129 PRNP which suggests susceptibility to v-CJD is not confined to homozygous PRNP genotypes. This observation has implications for future estimations of the number of CJD cases in the $\mathrm{UK}$, as the heterozygote genotype constitutes the largest genetic subgroup in the population [16]. This has raised concerns over the safeguarding of the blood supply, with potentially many asymptomatic carriers unknowingly donating blood. To date a positive diagnosis for prion diseases requires a post-mortem examination of brain tissue after full clinical stage symptoms are shown. The diseases are positively identified if $\mathrm{PrP}^{\mathrm{Sc}}$ aggregation is observed. The development of a noninvasive highly sensitive preclinical diagnostic test for prion diseases is highly desirable not only to stop the spread of the disease but also may lead to better clinical outcomes in the future. A potentially interesting experimental approach involves the detection of altered structures of the prion protein.

Various analytical methods have been used for the structural characterization of prions extracted from in vivo material and recombinant proteins. Spectroscopic techniques such as circular dichroism (CD), Fourier transform infrared (FTIR), nuclear magnetic resonance (NMR) spectroscopy, and electron paramagnetic resonance (EPR) spectroscopy are widely used in prion research. The use of mass spectrometry (MS) to analyze the primary structure of $\operatorname{PrP}$ and post-translational modifications has been well documented [17-24]. When MS is combined with soft ionization methods, such as electrospray ionization (ESI), detailed molecular structural information can be obtained. An analytical challenge is introduced when MS is used to analyze proteins that differ in structure, but are isobaric in molecular weight. Recent developments in the field of MS have seen the coupling of ion mobility spectrometry (IMS) to MS instruments. This has lead to the development of a powerful methodology which provides a potential technique to investigate the different structures of $\mathrm{PrP}$ with the prospect of developing a future diagnostic test for prion diseases.

Ion mobility describes the motion of a gaseous ion through a drift cell that is filled with an inert buffer gas, under high-pressure, under the influence of an electric field. Compact ions with small collision cross-sections will drift more quickly than extended ions. The mea- surement of this mobility yields information about the rotationally-averaged cross-section (i.e., whether it is compact or extended) of each ion. IM-MS has the potential to differentiate between monomeric and oligomeric forms of the predominantly $\alpha$-helical $\operatorname{PrP}^{\mathrm{C}}$ and the $\beta$-sheet-rich isoforms. Here, we have used two forms of IM-MS; traveling-wave (T-Wave) ion mobility and direct-current ion mobility (DCIM) mass spectrometry. T-Wave technology has been integrated into a quadrupole time-of-flight instrument to create the commercially available Synapt HDMS system (Waters, Manchester, UK), the DCIM technology used here has been created in-house by the Bowers group [25]. The T-Wave device has a number of potential advantages when compared to DCIM approaches, because of its high sensitivity and ability to simultaneously collect mass spectra data and arrival time distribution information. The physical principles behind DCIM are well characterized and data obtained can be used to measure the absolute collision cross-section of an ion. Mobility separation obtained by means of the T-Wave technology depends on a number of different variables including complex ion trajectories, collisions with the buffer gas and the time-dependent non-uniform electric field of the T-Wave cell. Due to these features of the T-Wave technology, absolute collision cross-sections of an ion can not be obtained directly from mobility measurements. To compare the results from the two mobility techniques a calibration method for the T-Wave technology has been developed [26]. This calibration produces an estimated cross-section based on the measurement of the mobility of reference standards of known cross-sections obtained under similar experimental conditions.

Here, we present a combination of ESI with ion mobility (IM) to generate structural information on recombinant Syrian hamster prion protein $\mathrm{SHaPrP}(90-$ 231). The PrP sequence is highly conserved throughout the mammalian species with 18 different amino acid residues between the full-length human and Syrian hamster prion protein primary structure. The $\mathrm{SHaPrP}(90-231)$ samples have been refolded to an $\alpha$-helical structure representative of $\operatorname{PrP}^{\mathrm{C}}$ and one rich in $\beta$-sheet content representative of $\mathrm{PrP}^{\mathrm{Sc}}$-like structure. Separation of $\alpha$-helical and $\beta$-sheet-rich $\mathrm{SHaPrP}(90-231)$ isoforms, with the same nominal $\mathrm{m} / \mathrm{z}$ ratio but differing structure, was possible using ion mobility. The rotationally-averaged cross-section was calculated. We have evaluated the potential of ion mobility for the shape-directed selection of the conformational isoforms and the prospect of using IM-MS as a new ante-mortem diagnostic test.

\section{Experimental}

Expression, Purification, and Refolding of $\operatorname{Pr} P$

Recombinant Syrian hamster prion protein $\mathrm{SHaPrP}(90-$ 231) was expressed using an alkaline phosphatase pro- 
moter in a protease-deficient strain of Escherichia coli [27]. The prion protein was purified from inclusion bodies and refolded into an $\alpha$-helical structure under oxidizing conditions, as previously described [28].

The conversion of $\alpha$-SHaPrP(90-231) to $\beta$-sheet-rich structures was carried out using a similar protocol to that described by Martins et al. [29]. $100 \mu \mathrm{M}$ recombinant $\alpha$-SHaPrP(90-231) in $5 \mathrm{mM}$ ammonium formate, $\mathrm{pH} 5.5$ buffer was incubated at $70^{\circ} \mathrm{C}$ for $24 \mathrm{~h}$.

\section{Infrared Spectroscopy}

Attenuated total reflection (ATR) Fourier transform infrared (FTIR) spectra were acquired on a Bruker Vector 22 spectrometer equipped with a liquid nitrogen cooled mercury cadmium telluride (MCT) detector (Bruker, Coventry, UK). Spectra were recorded at room temperature at a nominal resolution of $4 \mathrm{~cm}^{-1}$ in the range $4000-1000 \mathrm{~cm}^{-1}$. The spectral contribution of atmospheric water was minimized by the continuous purging of the sample chamber with dried air (Jun-Air, Kent, UK). Residual water vapor peaks were subtracted using reference spectra and baseline correction was applied when necessary. The internal reflection element was a germanium ATR plate $(50 \times 20 \times 2 \mathrm{~mm})$ with an aperture angle of $45^{\circ}$, yielding 25 internal reflections.

A $50 \mu \mathrm{L}$ aliquot of sample containing $\sim 10 \mu \mathrm{M}$ $\mathrm{SHaPrP}(90-231)$ in $5 \mathrm{mM}$ ammonium formate buffer, pH 5.5, was deposited on the ATR plate. A thin hydrated protein film was obtained by slowly evaporating the excess water under a stream of $\mathrm{N}_{2}$ gas. All ATR FTIR spectra were collected after a short period of $\mathrm{H}_{2} \mathrm{O} / \mathrm{D}_{2} \mathrm{O}$ exchange to aid the analysis of protein secondary structure [30]. Deposited protein films were subjected to a stream of $\mathrm{D}_{2} \mathrm{O}$-saturated nitrogen gas for $10 \mathrm{~min}$.

\section{Circular Dichroism}

Far-UV (190-260 nm) CD spectra of SHaPrP(90-231) (10 $\mu \mathrm{M})$ were measured on a JASCO J-815 spectropolarimeter using $1 \mathrm{~mm}$ path length quartz cuvettes. Typically, a scanning rate of $100 \mathrm{~nm} / \mathrm{min}$, a time constant of $1 \mathrm{~s}$, and a bandwidth of $1.0 \mathrm{~nm}$ were used. Spectra were measured at $20 \pm 0.2^{\circ} \mathrm{C}$, with a resolution of $0.5 \mathrm{~nm}$, and 16 scans were averaged per spectrum. The buffer background was subtracted from the final spectra. Samples were analyzed immediately after recombinant $\alpha$-SHaPrP(90-231) in $5 \mathrm{mM}$ ammonium formate, $\mathrm{pH} 5.5$ buffer was incubated at $70{ }^{\circ} \mathrm{C}$ for $24 \mathrm{~h}$ to determine the secondary structure. $\beta$-sheet-rich $\mathrm{SHaPrP}(90-231)$ spectra were recorded before and after 15 min sonication in a bath sonicator.

\section{Electron Microscopy}

Stock solutions of $\beta \mathrm{SHaPrP}(90-231)$ were diluted to a protein concentration of $50 \mu \mathrm{g} / \mathrm{mL}$ in $5 \mathrm{mM}$ ammonium formate buffer, $\mathrm{pH}$ 5.0, applied to EM grids coated with carbon film, and stained with $2 \%$ uranyl acetate. The samples were viewed in a Philips CM120 electron microscope equipped with a LaB6 filament and a voltage of $100 \mathrm{kV}$ (Philips, Surrey, UK). Images were acquired at a magnification of 45,000.

\section{Drift Cell Ion Mobility Mass Spectrometry}

The home-built instrument used to measure the collision cross-sections has been described in detail elsewhere [25] and was operated in positive ion mode. Ions were formed using ESI and a short pulse of ions was transferred to the drift cell filled with helium at a pressure of 5 Torr. A quadrupole mass filter was used to mass select ions exiting the drift cell. Selected ions were detected as a function of their arrival time. The ion arrival time distributions (ATDs), length of the drift cell, drift voltage, temperature, and helium pressure were used to calculate cross-sections [31].

\section{T-Wave Ion Mobility-Mass Spectrometry}

All IM-MS experiments were performed in a hybrid quadrupole-ion mobility-orthogonal acceleration timeof-flight (oa-TOF) mass spectrometer (Synapt HDMS; Waters, Manchester, UK). The instrument was equipped with a nanoflow electrospray ion source and operated at a source temperature of $90{ }^{\circ} \mathrm{C}$. The sample solutions were introduced into the source region of the instrument by direct infusion ESI. The cone voltage was optimized at $40 \mathrm{~V}$ for ESI-MS experiments. A detailed explanation of the Synapt HDMS technology has been described elsewhere [32]. Briefly, the machine consists of three traveling wave (T-Wave) enabled stacked ion guides called the: trap, IM cell, and transfer. The trap ion guide is used to accumulate ions and releases these as ion packets into the IM cell for mobility separation. The transfer ion guide is used to convey the mobilityseparated ions to the oa-TOF mass analyzer [32]. The pressure in the T-Wave IM cell was 0.55 mbar in these experiments, with nitrogen employed as the mobility gas. The T-Wave height and velocity were set at $9 \mathrm{~V}$ and $300 \mathrm{~m} / \mathrm{s}$, respectively.

The TOF analyzer recorded 200 orthogonal acceleration pushes (mass spectra) with the pusher frequency set at $90 \mu \mathrm{s}$. This resulted in each IM experiment being performed over a $18.0 \mathrm{~ms}$ time frame. The TOF analyzer was tuned in $\mathrm{V}$-optic mode for an operating resolution of 7000 (FWHM). Data were acquired at an acquisition rate of two spectra/s with an interscan delay of $100 \mathrm{~ms}$. Data acquisition and processing were carried out using MassLynx (ver. 4.1) software (Waters Corp., Milford, MA, USA).

\section{T-Wave Cross-Section Calibration}

Methods to create a cross-section calibration for the T-Wave Synapt have been previously published [26, 32-36]. The calibration was performed following an 
in-house procedure as described in Thalassinos et al. [26]. In brief, equine myoglobin (Sigma-Aldrich, Gillingham, UK) was diluted to a concentration of $10 \mu \mathrm{M}$ in $50 \%$ aqueous acetonitrile $/ 0.1 \%$ formic acid (Mallinckrodt Baker Inc., Phillipsburg, NJ, USA) and analyzed against values obtained from drift-time ion mobility mass spectrometry (DTIMS) studies [37]. The arrival times obtained were corrected to exclude time spent outside of the IM T-Wave. Mass-independent time spent in the transfer region and mass-dependent time spent in the transfer region and TOF mass analyzer were subtracted. Normalized cross-sections (corrected for charge and reduced mass) were then plotted against corrected arrival times to create a calibration with a power series fit. When calibrating the Synapt with smaller molecules such as peptides, a linear relationship has been found to be more appropriate [26]. The rotationally averaged collision cross-sections were estimated for $\mathrm{SHaPrP}(90-231)$ under different $\mathrm{pH}$ conditions. When using this approach, corrected arrival times of the calibrants must span the corrected arrival times of the components to be calibrated. This should not be confused with the calibrant cross-section range spanning the cross-sectional range of the component to be calibrated [38]. For the prion proteins studied here, the relationship between corrected arrival times and published arrival times is best approximated by a power fit. An Excel spreadsheet used to simplify the creation and use of a cross-sectional calibration is available to download from the website (http://www2.warwick.ac.uk/ fac/sci/bio/research/jscrivens/).

\section{Electrospray Ionization-Mass Spectrometry}

All ESI-MS experiments were performed in a quadrupole orthogonal acceleration-time-of-flight (Qoa-TOF) mass spectrometer (Q-TOF I; Waters, Manchester, UK). The instrument was equipped with a nanoflow electrospray ion source and operated at a source temperature of $80^{\circ} \mathrm{C}$. The sample solutions were introduced into the source region of the instrument by direct infusion. The cone voltage was optimized at $40 \mathrm{~V}$.

The ToF analyzer was tuned in V-optic mode for an operating resolution of 5000 (FWHM). Mass spectra were acquired at an acquisition rate of two spectra/s with an interscan delay of $100 \mathrm{~ms}$. Data acquisition and processing were carried out using MassLynx (ver. 4.0) software (Waters).

\section{Sample Preparation (ESI)}

Ammonium formate was obtained from Sigma-Aldrich (Gillingham, UK). SHaPrP(90-231) samples were diluted to a concentration of $10 \mu \mathrm{M}$ in $10 \mathrm{mM}$ ammonium formate $\mathrm{pH}$ 5.5. The protein was analyzed at two $\mathrm{pH}$ values, $\mathrm{pH} 5.5$ and $\mathrm{pH}$ 7.0. The $\mathrm{pH}$ of each sample was increased to $\mathrm{pH} 7.0$ by the addition of $0.1 \%$ ammonia solution. ESI-MS analysis was performed by infusing a solution of $\mathrm{SHaPrP}(90-231)$ samples at $\mathrm{pH} 5.5$ and $\mathrm{pH}$
7.0. Samples high in $\beta$-sheet content were sonicated for $15 \mathrm{~min}$ before ESI-MS analysis and were sprayed immediately.

\section{Results and Discussion}

During its short life span $(3-6 \mathrm{~h})$ [39-42], the prion protein can experience two different $\mathrm{pH}$ environments; a mildly acidic environment, whilst cycling within the cell, and a neutral environment when it is GPI-anchored to the cell membrane. The prion conformational isoforms studied were $\alpha$-helical $\operatorname{SHaPrP}(90-231)$ and $\beta$-sheet-rich $\mathrm{SHaPrP}(90-231)$ at physiological $\mathrm{pH} 5.5$ and $\mathrm{pH}$ 7.0. Both conformational isoforms have the same nominal $\mathrm{m} / \mathrm{z}$ ratio but differ in their secondary structure. MS alone is not able to resolve oligomers with the same nominal $\mathrm{m} / \mathrm{z}$ ratio, regardless of their shape. Figure 1 shows the mass spectra of $\alpha$-helical SHaPrP(90231 ) and $\beta$-sheet-rich $\mathrm{SHaPrP}(90-231)$ at $\mathrm{pH}$ 5.5. A comparison of the MS spectra indicates the charge state envelope distributions of the two datasets are similar. The labels on the peaks $(7+, 8+$, etc. $)$ indicate the charge $(z)$ of the ion species. The deconvoluted peak (see insets) derived from each sample corresponded to the predicted molecular mass of oxidized $\mathrm{SHaPrP}(90-$ 231), $16,240 \mathrm{Da}$. This is considered to be more biologically relevant than its reduced counterpart $[3,43]$. This is because the oxidized construct is structured due to the presence of a disulphide bond. This disulphide bond has been observed in both conformational isoforms.

The conversion of $\operatorname{PrP}^{\mathrm{C}}$, a protein that is predominantly $\alpha$-helical, to a $\beta$-sheet-rich isoform that has a propensity to aggregate, is the key molecular event in prion diseases. Recombinant prion protein can be refolded into a monomeric $\alpha$-helical conformer, $\alpha$ $\mathrm{SHaPrP}(90-231)$, or to a $\beta$-sheet-rich structure. Refolding of PrP under oxidizing non-denaturing conditions at $\mathrm{pH} 5.5$ yields an $\alpha \mathrm{SHaPrP}(90-231)$ isoform. This isoform shows a characteristic far-UV CD spectrum with well defined minima at $208 \mathrm{~nm}$ and $222 \mathrm{~nm}$ (Figure 2a) and also a FTIR spectrum containing a symmetrical amide I band with a maximum at $\sim 1660 \mathrm{~cm}^{-1}$ (Figure $2 b)$. The CD and FTIR results are consistent with a protein containing a significant amount of $\alpha$-helical structure. Incubation of $\alpha \mathrm{SHaPrP}(90-231)$ at $70^{\circ} \mathrm{C}$ for $24 \mathrm{~h}$ induces a structural transition from a protein that is mainly $\alpha$-helical to one that has increased $\beta$-sheet structure [29]. In contrast to $\alpha \operatorname{SHaPrP}(90-231)$, the $\beta$-sheet-rich $\mathrm{SHaPrP}(90-231)$ isoform produced a far-UV $\mathrm{CD}$ spectrum with a minimum at $\sim 217 \mathrm{~nm}$ (Figure 2a), which is indicative of a substantial increase in $\beta$-sheet structure. The amide I band in the FTIR spectrum of $\beta$ $\mathrm{SHaPrP}(90-231)$ is also significantly different from that of $\alpha \mathrm{SHaPrP}(90-231)$, the appearance of a distinct band at $1627 \mathrm{~cm}^{-1}$ is characteristic of $\beta$-sheet structure (Figure $2 \mathrm{~b}$ ). Examination of the $\beta$-sheet-rich isoform of $\mathrm{SHaPrP}(90-231)$ under the electron microscope revealed the presence of ordered aggregates. EM showed flexible 


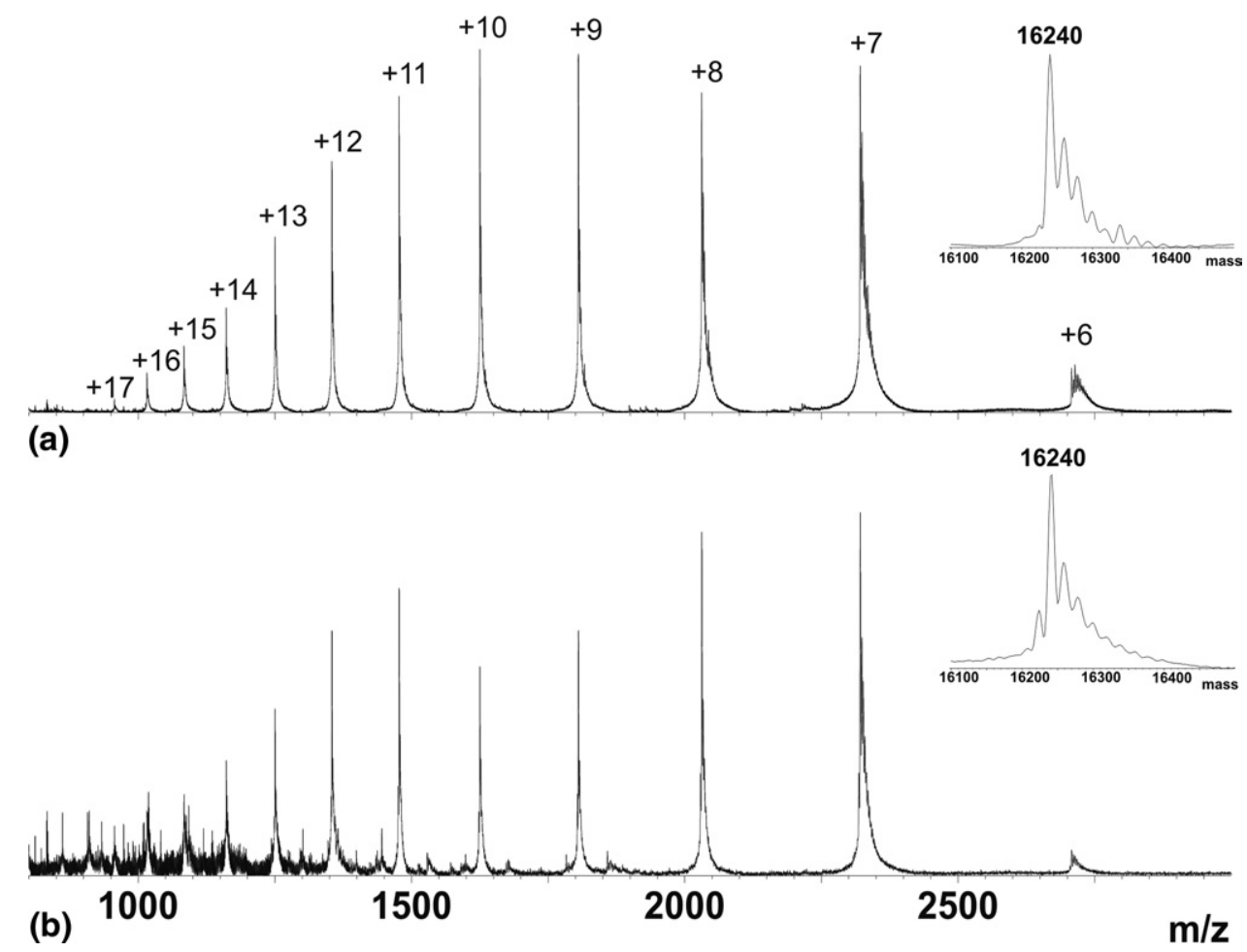

Figure 1. (a) Mass spectrum of $\alpha-\mathrm{SHaPrP}(90-231)$ at $\mathrm{pH}$ 5.5. Inset: Deconvoluted mass of prion protein suggesting it is the oxidized form. (b) Mass spectrum of $\beta \mathrm{SHaPrP}(90-231)$ at $\mathrm{pH}$ 5.5. Inset: Deconvoluted mass of prion protein suggesting it is the oxidized form.

fibrillar type structures of varying lengths with an average diameter of $10 \mathrm{~nm}$ (Figure 2c). Direct analysis of these $\beta$-sheet-rich $\mathrm{SHaPrP}(90-231)$ structures by means of ESI-IM-MS was challenging due to the difficulty of obtaining a stable spray. To overcome this problem the sample was sonicated for $15 \mathrm{~min}$ in an ultrasonic bath, resulting in lower molecular weight molecules which could then be directly infused into the IM-MS. Analysis of the sonicated $\beta$ SHaPrP(90-231) sample by means of $C D$ showed no change in the secondary structure of the protein upon sonication (Figure 2a) although the EM images suggested that the large protein aggregates were broken into smaller structures (Figure 2c).

Several hypotheses have been outlined, which suggest that the $\alpha$-helical PrP can undergo a conformational change to form a variety of $\beta$-sheet-rich isoforms $[44,45]$. It is these $\beta$-sheet-rich isoform deposits from $\mathrm{PrP}^{\mathrm{Sc}}$ that are associated with prion disease. The monomeric $\beta$-sheet-rich PrP sample prepared for this experimental dataset is likely to be one of a number of possible structures observed in vitro and in vivo. It has been observed, by means of CD and EM (Figure 2), that the $\beta$-sheet-rich $\operatorname{PrP}$ sample had a propensity to aggregate and form high order oligomers. Monomeric/low oligomeric material is required for nanoflow mass spectrometry analysis, as it was observed that higher order oligomers blocked the sample tip. The formation of monomeric $\beta$-sheet-rich PrP (after 15 min sonication) could be considered a transient form of the aggregating protein. Sonication of the prion is used in high order oligomeric seeding experiments such as prion misfolding cyclic amplification (PMCA) experiments which were first described by Castilla et al., 2005 [46]. It is postulated that the monomeric $\beta$-sheet protein has a finite lifetime. A rapid and selective approach is therefore required to capture the monomeric $\beta$-sheet form, under near native conditions, when the PrP sample has been sonicated.

The $\alpha \mathrm{SHaPrP}(90-231)$ at $\mathrm{pH} 7.0$ was analyzed using both the T-Wave technology (Synapt) and a DCIM instrument built in-house by the Bowers group [25]. DCIM absolute cross-sections for $\alpha \operatorname{SHaPrP}(90-231)$ at pH 7.0 in ammonium formate buffer agree with previously published cross-sections of the same protein but in a different buffer [47]. A comparison of the estimated and absolute cross-sections, from charge states $[\mathrm{M}+$ $7 \mathrm{H}]^{7+}$ to $[\mathrm{M}+15 \mathrm{H}]^{15+}$, is shown in Table S-1 (see supplementary data, which can be found in the electronic version of this article). DCIM measurements were obtained using helium, as the buffer gas, at a pressure of 5 Torr whereas all Synapt experiments were performed using nitrogen at a pressure of 0.55 mbar. Despite the difference in buffer gas and pressure used, there is an excellent agreement between the two techniques which has also been observed elsewhere [26]. The SHaPrP(90-231) samples rich in $\beta$-sheet content had a propensity to aggregate and were analyzed immediately after their conversion from the $\alpha$-helical form. It was observed that, on average, the sonicated $\beta$ 


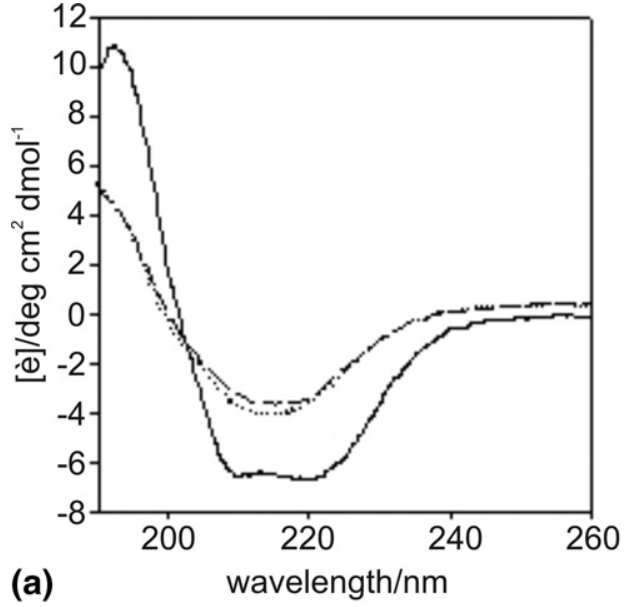

(a)

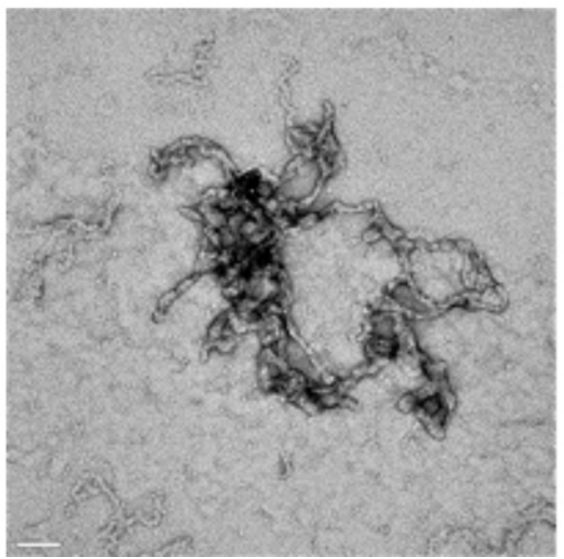

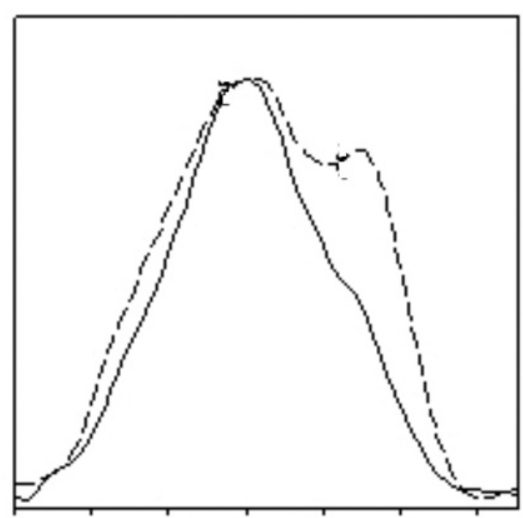

1720170016801660164016201600

(b)

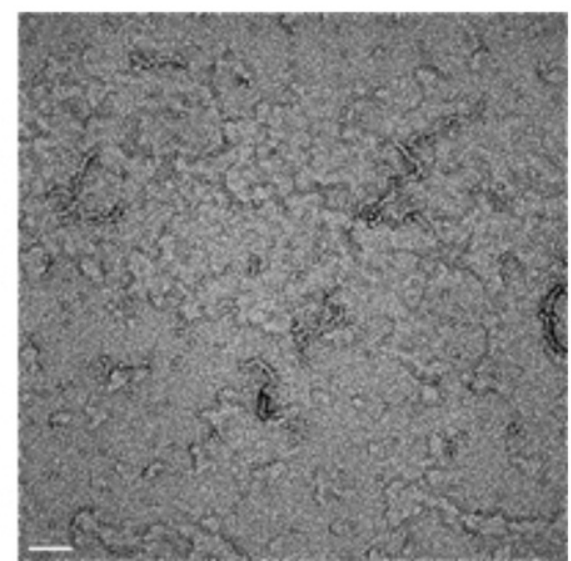

Figure 2. Conformational properties of different PrP states. Secondary structure of PrP; (a) Far-UV CD spectra of $\alpha$-helical $\operatorname{PrP}$ (solid line), $\beta$-sheet-rich $\operatorname{PrP}$ (dashed line), and following sonication (dotted line), and (b) ATR FTIR spectra of $\alpha$-helical $\operatorname{PrP}$ (solid line) and $\beta$-sheet-rich $\operatorname{PrP}$ (dashed line). (c) Morphology of $\beta$-sheet-rich PrP aggregates. Electron micrographs of negatively stained $\beta$-sheet-rich $\operatorname{PrP}$ aggregates before (left panel) and after sonication (right panel). The bar scale is $50 \mathrm{~nm}$.

SHaPrP(90-231) sample started to aggregate after a few minutes of spraying. These aggregates blocked the sample tip and prevented further data being collected. An advantage of the Synapt is its ability to simultaneously collect mass spectral data and arrival time distribution (ATD) information. This allows data to be collected in a relatively short time scale. The total Synapt IM acquisition time for the data shown was combined and the data were averaged over five minutes enabling high quality data to be obtained before the sample tip blocked. In contrast, the experimental time required to obtain the equivalent data on the DCIM instrument is significantly longer (due to the scanning nature inherent to quadrupole mass analysis) therefore, the Synapt was the preferred technology to analyze the $\beta$-sheet-rich $\mathrm{SHaPrP}(90-231)$. The MS experimental time period is crucial in the maintenance of solution-phase structure. It has been shown that, within a time scale of 30-60 ms, the gas-phase structures of proteins can rearrange to account for their change in environment [48]. The Synapt experiments operate within a 15-30 ms time frame [49], which limits the opportunity for the protein solution-phase structures to rearrange within the gas-phase. The good agreement between the DCIM and Synapt results suggest similar structures are being measured by both techniques.

Grabenauer et al. have previously measured the absolute cross-sections of $\alpha \mathrm{SHaPrP}(90-231)$ at $\mathrm{pH} 7.0$ by means of DCIM [47]. A comparison of these crosssections with data obtained at $\mathrm{pH} 5.5$, in this study, showed that there were no significant differences in the cross-section of the protein under the two physiological conditions. These findings suggest that the truncated core structure of the prion protein is similar at the two different $\mathrm{pH}$. In vivo studies suggest that the newly synthesized $\operatorname{PrP}^{\mathrm{C}}$ is released from the mildly acidic endoplasmic reticulum, $\sim \mathrm{pH} 5.5$, and journeys to its final position on the cell membrane, under $\mathrm{pH} 7.0$ conditions, where it matures [50]. It is essential that the $\operatorname{PrP}^{\mathrm{C}}$ structure is highly conserved throughout the protein's biosynthesis as a small fluctuation in its structure could catalyze the conversion of $\mathrm{PrP}^{\mathrm{C}}$ to $\mathrm{PrP}^{\mathrm{Sc}}$ [51].

Both conformational isoforms at $\mathrm{pH} 5.5$ were directly infused after ionization by means of ESI into the Synapt 


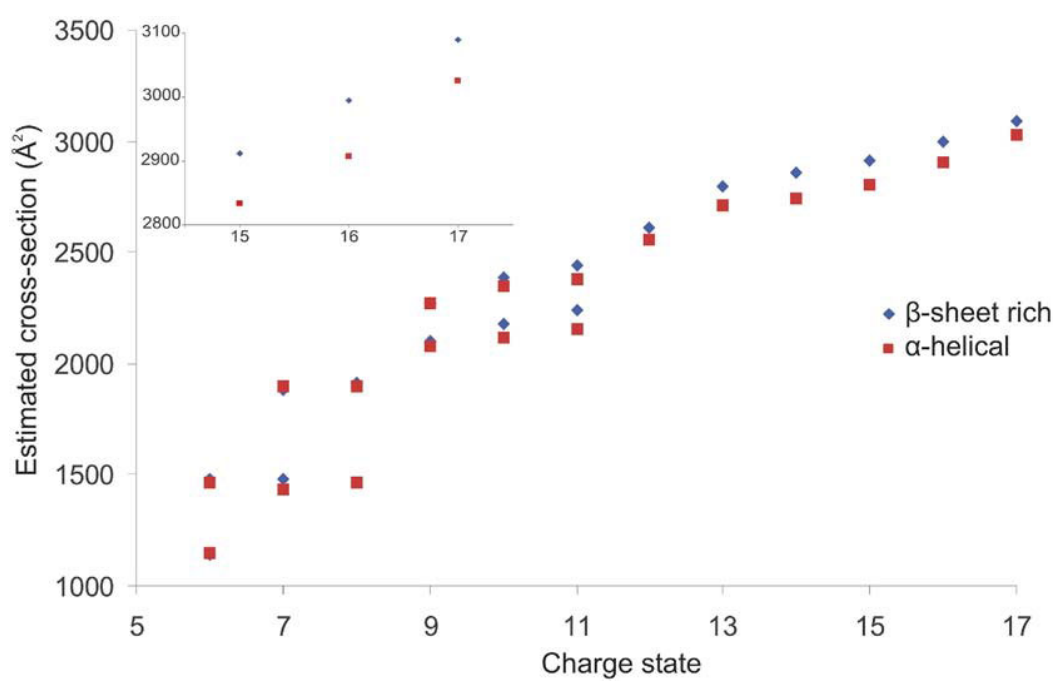

Figure 3. Comparison of estimated cross-sections for different charge states of $\alpha$-helical (red) and predominantly $\beta$-sheet (blue) $\mathrm{SHaPrP}(90-231)$, at $\mathrm{pH}$ 5.5. Inset: Enlarged image of charge states $[\mathrm{M}+$ $15 \mathrm{H}]^{15+}$ to $[\mathrm{M}+17 \mathrm{H}]^{17+}$ showing the differences in the estimated cross-sections between the $\alpha$-helical and predominantly $\beta$-sheet conformational isoforms.

mass spectrometer (in two separate experiments). Figure 3 shows the estimated cross-sections for the [M + $6 \mathrm{H}]^{6+}$ to $[\mathrm{M}+17 \mathrm{H}]^{17+}$ charge states at $\mathrm{pH} 5.5$ and the enlargement is of the data of the $[\mathrm{M}+15 \mathrm{H}]^{15+}$ to $[\mathrm{M}+$ $17 \mathrm{H}]^{17+}$ charge states (see inset). Separation of the two isobaric conformational isoforms and their corresponding mass spectra were obtained from the same experiment. There are small differences in the estimated cross-sections $(\sim 3 \%)$ between the $\alpha$-helical SHaPrP(90231) and the $\beta$-sheet-rich $\operatorname{SHaPrP}(90-231)$ from charge states $[\mathrm{M}+13 \mathrm{H}]^{13+}$ to $[\mathrm{M}+17 \mathrm{H}]^{17+}$. The charge states of $\alpha$-helical $\mathrm{SHaPrP}(90-231)$ appear to have smaller
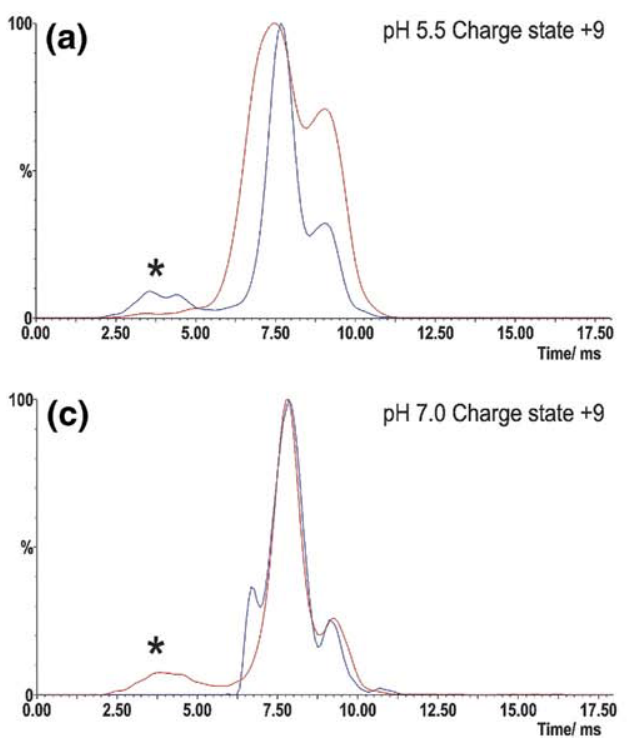

rotationally averaged cross-sections than that of the $\beta$-sheet-rich SHaPrP(90-231). Upon the sequential addition of protons the conformational isoforms become less compact in structure.

At the lower charge states, no significant differences in the rotationally-average cross-section were observed. The ATD profiles for individual charge states were examined and showed a clear distinction between the two isomeric samples. Figure 4 shows a comparison of the $\alpha$-helical and $\beta$-sheet-rich SHaPrP(90-231) ATDs at $\mathrm{pH} 5.5$ for charge states $[\mathrm{M}+9 \mathrm{H}]^{9+}$ and $[\mathrm{M}+10 \mathrm{H}]^{10+}$. The peaks labeled with an asterisk were not included in
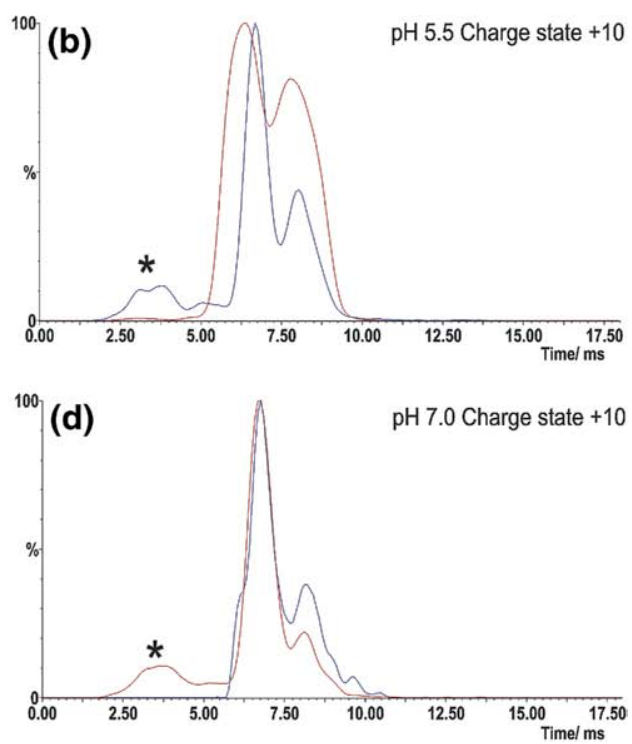

Figure 4. Comparison of $\alpha$-helical (red) and predominantly $\beta$-sheet (blue) SHa PrP(90-231) selected arrival time distributions (ATDs) for charge state $[\mathrm{M}+9 \mathrm{H}]^{9+}$ and $[\mathrm{M}+10 \mathrm{H}]^{10+}$. (a) Overlaid ATDs for charge state $[\mathrm{M}+9 \mathrm{H}]^{9+}$ at $\mathrm{pH}$ 5.5. (b) Overlaid ATDs for charge state $[\mathrm{M}+10 \mathrm{H}]^{10+}$ at $\mathrm{pH} 5.5$. (c) Overlaid ATDs for charge state $[\mathrm{M}+9 \mathrm{H}]^{9+}$ at $\mathrm{pH}$ 7.0. (d) Overlaid ATDs charge state $[\mathrm{M}+$ $10 \mathrm{H}]^{10+}$ at $\mathrm{pH}$ 7.0. Peaks labeled with an asterisk are not included in the estimated cross-section plot. 
the estimated cross-section plot in Figures 3 or 5. The $\alpha$-helical charge state $[\mathrm{M}+9 \mathrm{H}]^{9+}$ (Figure 4a) ATD is $60 \%$ broader at full-width half-height maximum (FWHM) than that of the $\beta$-sheet form. The FWHM described is the combined width of the two resolvable conformations observed in Figure 4a. There is also a $40 \%$ increase in the intensity of the secondary peak in $\alpha$-helical species relative to that of the $\beta$-sheet ATD. These differences are particularly noticeable when the individual ATDs are overlaid. Similar observations have been made for the $[\mathrm{M}+10 \mathrm{H}]^{10+}$ charge state see Figure $4 \mathrm{~b}$. The relatively large width of the $\alpha$ SHaPrP(90-231) ATD suggests that there are multiple conformations present which may have a difference in cross-section of $<3 \%$. It is expected that cross-sections that are greater than $3 \%$ in difference would be resolved by this ion mobility approach [33].

The $\mathrm{pH}$ of each sample was increased to $\mathrm{pH} 7.0$ by the addition of a $0.1 \%$ ammonia solution and infused into the Synapt mass spectrometer. Figure 5 shows the estimated cross-sections for charge states $\left([\mathrm{M}+6 \mathrm{H}]^{6+}\right.$ to $[\mathrm{M}+17 \mathrm{H}]^{17+}$ ) obtained at $\mathrm{pH} 7.0$ and the enlargement is of the data of the charge states $[\mathrm{M}+15 \mathrm{H}]^{15+}$ to $[\mathrm{M}+17 \mathrm{H}]^{17+}$ (see inset). The degree of protein unfolding, as sequential protons are added, is indicated by an increase in estimated cross-section with increasing charge state. The unfolding of the prion is similar under the two physiological $\mathrm{pH}$ conditions used. Multiple stable conformations are observed under both $\mathrm{pH}$ conditions from charge states $[\mathrm{M}+6 \mathrm{H}]^{6+}$ to $[\mathrm{M}+11 \mathrm{H}]^{11+}$. Two conformations were observed for charge state $[\mathrm{M}+8 \mathrm{H}]^{8+}$ at $\mathrm{pH} 7.0$, however, one conformation is dominant and the only one considered here. The multiple conformations observed here are consistent with those observed by DCIM-MS (see Table S-1). At charge states $\geq+12$ it was observed that the FWHM of individual ATDs decreased as sequential protons were added. This suggests that the number of distinct conformations at the higher charge states is reduced or that all conformations have similar cross-sections. An instrument performance validation was performed, using equine myoglobin and $\alpha$-helical SHaPrP(90-231) at $\mathrm{pH}$ 7.0, to check the reproducibility and precision of the ATD profiles and estimated cross-sections throughout all the experiments (see Figure S-1, for myoglobin reproducibility). These validation experiments were performed before any IM-MS conformational isoform studies and showed that the ATD data were reproducible within \pm 1 scan. The measured experimental variation indicated that the differences observed between $\alpha$-helical SHaPrP(90-231) $\mathrm{pH} 5.5$ and $\beta$-sheet-rich $\mathrm{SHaPrP}(90-231) \mathrm{pH} 5.5$ were because of differences in the sample conformation rather than experimental error. The differences observed in the conformation disappeared when the $\mathrm{pH}$ of the sample was increased.

Figure 5 shows there is no significant difference in the estimated cross-sections between the $\alpha$-helical and $\beta$-sheet-rich conformers at $\mathrm{pH}$ 7.0. At the higher charge states, $[\mathrm{M}+15 \mathrm{H}]^{15+}$ to $[\mathrm{M}+17 \mathrm{H}]^{17+}, \sim 100 \AA^{2}$ separates the two isoforms at $\mathrm{pH} 5.5$, whereas $\leq 10 \AA^{2}$ separates the $\alpha$ - and $\beta$-SHaPrP(90-231) at $\mathrm{pH} 7.0$. Examination of the individual ATDs at $\mathrm{pH} 7.0$ revealed there were no differences in the shape, size, or intensity of the peaks. Figure $4 \mathrm{c}$ and $\mathrm{d}$ show a comparison of ATDs for the $[\mathrm{M}+9 \mathrm{H}]^{9+}$ and $[\mathrm{M}+10 \mathrm{H}]^{10+}$ charge states which suggest that both isoforms at $\mathrm{pH} 7.0$ have similar conformations to the $\beta$-sheet-rich $\mathrm{SHaPrP}(90-231)$ at $\mathrm{pH}$ 5.5.

ESI-MS experiments were carried out for both $\alpha$ helical and $\beta$-sheet-rich $\mathrm{SHaPrP}(90-231)$ under the two different $\mathrm{pH}$ conditions (without any ion mobility separation) using a standard oa-TOF mass spectrometer. A comparison of the MS data, obtained directly and as a summation of the 200 spectra acquired in the T-Wave

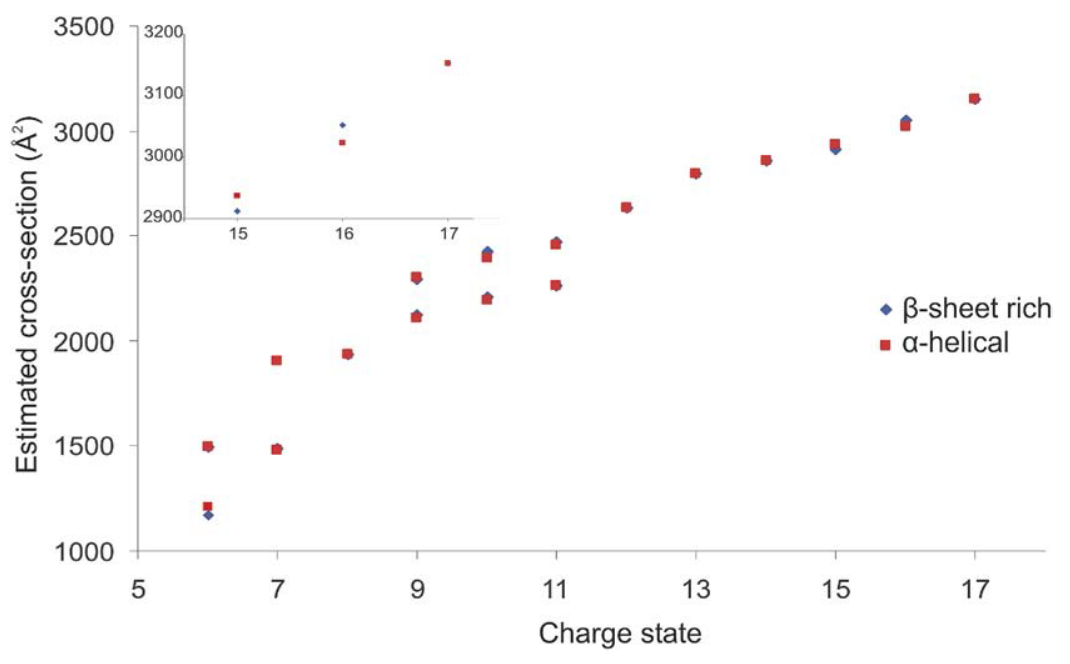

Figure 5. Comparison of estimated cross-sections for different charge states of $\alpha$-helical (red) and predominantly $\beta$-sheet (blue) $\mathrm{SHa} \operatorname{PrP}(90-231)$, at $\mathrm{pH}$ 7.0. Inset: Enlarged image of charge states $[\mathrm{M}+$ $15 \mathrm{H}]^{15+}-[\mathrm{M}+17 \mathrm{H}]^{17+}$ shows no differences in the estimated cross-sections between the $\alpha$-helical and predominantly $\beta$-sheet conformational isoforms. 
technology, indicates there is good agreement between the two sets of spectra (data not shown). This is indicative of full separation of the conformational isoforms in the ion mobility cell and that good quality MS data can be obtained using IM-MS.

\section{Conclusions}

ESI-IM-MS has been used to study two recombinant isobaric prion conformational isoforms at relevant physiological pHs: $\alpha$-helical SHaPrP(90-231) and $\beta$-sheet-rich SHaPrP(90-231) at $\mathrm{pH} 5.5$ and $\mathrm{pH}$ 7.0. CD and ATR FTIR information characterized the secondary structure of the proteins whilst EM data observed the aggregation. The presence of a $\beta$-sheet-rich $\mathrm{SHaPrP}(90-231)$ conformation was further suggested by the ready aggregation of the sample necessitating sonication of the sample solution before any IM-MS experiments. There is good agreement between the Synapt estimated crosssections and the DCIM absolute cross-sections for the $\alpha$-helical SHaPrP(90-231). The use of ion mobility as a shape-selective separation technique has enabled the differentiation of the recombinant $\alpha$-helical SHaPrP(90231) and $\beta$-sheet-rich $\mathrm{SHaPrP}(90-231)$ conformational isoforms at $\mathrm{pH}$ 5.5. While the differences in crosssections were small $(\sim 3 \%)$ the resulting ATD profiles were significantly different at this $\mathrm{pH}$. No differences in cross-section or ATD profiles were observed between the protein isoforms at $\mathrm{pH}$ 7.0. This strengthens the observation of differences in the ATD profiles at $\mathrm{pH}$ 5.5. It was observed that the change in $\mathrm{pH}$ environment had a greater influence on the cross-section of the $\alpha$-helical isoform than the $\beta$-sheet-rich protein.

The T-Wave device is able to operate at biologically relevant sample concentrations and in conjunction with its speed of analysis and ease of use, it also has the ability to be used in an automated fashion. ESI-IM-MS provides an extra dimension of fast, sensitive, gasphase ion separation enabling conformational changes in the protein structure to be probed. The technique clearly has merit as a potential method of providing an ante-mortem screening assay of bodily fluids for protein misfolding diseases such as TSEs. The T-Wave device can also be used to study the differences in structural stability of a protein and cross-sections obtained from T-Wave data have been shown to be comparable to NMR spectroscopy and X-ray crystallographic studies [33].

\section{Acknowledgments}

The authors thank the electron microscopy suite at the University of Warwick, for their help and support in obtaining EM data. These studies were partly funded by the UK Food Standards Agency grant M03039. G.R.H. thanks the EPSRC for the award of a studentship, Intertek, and AkzoNobel, for their financial support.

\section{Appendix A Supplementary Material}

Supplementary material associated with this article may be found in the online version at doi:10.1016/ j.jasms.2010.01.017.

\section{References}

1. Collinge, J.; Palmer, M. S. Prion Diseases. Curr. Opin. Genet. Dev. 1992, 2(3), 448-454.

2. Prusiner, S. B. Novel Proteinaceous Infectious Particles Cause Scrapie. Science 1982, 21(4542), 136-144

3. Prusiner, S. B. Prions. Proc. Natl. Acad. Sci. U.S.A. 1998, 95(23), 13363 13383.

4. Stahl, N.; Baldwin, M. A.; Teplow, D. B.; Hood, L.; Gibson, B. W.; Burlingame, A. L.; Prusiner, S. B. Structural Studies of the Scrapie Prion Protein Using Mass Spectrometry and Amino Acid Sequencing. Biochemistry 1993, 32(8), 1991-2002.

5. Riek, R.; Hornemann, S.; Wider, G.; Glockshuber, R.; Wuthrich, K. NMR Characterization of the Full-Length Recombinant Murine Prion Protein, $\mathrm{mPrP}(23-231)$. FEBS Lett. 1997, 413(2), 282-288.

6. Donne, D. G.; Viles, J. H.; Groth, D.; Mehlhorn, I.; James, T. L.; Cohen, F. E.; Prusiner, S. B.; Wright, P. E.; Dyson, H. J. Structure of the Recombinant Full-Length Hamster Prion Protein $\operatorname{PrP}(29-231)$ : The NTerminus is Highly Flexible. Proc. Natl. Acad. Sci. U.S.A. 1997, 94(25), 13452-13457.

7. Zahn, R.; Liu, A.; Luhrs, T.; Riek, R.; von Schroetter, C.; Lopez Garcia, F.; Billeter, M.; Calzolai, L.; Wider, G.; Wuthrich, K. NMR Solution Structure of the Human Prion Protein. Proc. Natl. Acad. Sci. U.S.A. 2000, 97(1), 145-150.

8. Pan, K. M.; Baldwin, M.; Nguyen, J.; Gasset, M.; Serban, A.; Groth, D.; Mehlhorn, I.; Huang, Z.; Fletterick, R. J.; Cohen, F. E. Conversion of $\alpha$-Helices into $\beta$-Sheets Features in the Formation of the Scrapie Prion Proteins. Proc. Natl. Acad. Sci. U.S.A. 1993, 90(23), 10962-10966.

9. Dabaghian, R. H.; Mortimer, P.P.; Clewley, J. P. Prospects for the Development of Pre-Mortem Laboratory Diagnostic Tests for Creutzfeldt-Jakob Disease. Rev. Med. Virol. 2004, 14(6), 345-361.

10. Khamsi, R. Prion Disease: The Shape of Things to Come. Nature 2006, 439(7073), 134-135.

11. Brown, P.; Will, R. G.; Bradley, R.; Asher, D. M.; Detwiler, L. Bovine Spongiform Encephalopathy and Variant Creutzfeldt-Jakob Disease: Background, Evolution, and Current Concerns. Emerg. Infect. Dis. 1001, 7(1), 6-16.

12. Collinge, J. Variant Creutzfeldt-Jakob Disease. Lancet 1999, 354(9175), 317-323.

13. Llewelyn, C. A.; Hewitt, P. E.; Knight, R. S.; Amar, K.; Cousens, S.; Mackenzie, J.; Will, R. G. Possible Transmission of Variant CreutzfeldtJakob Disease by Blood Transfusion. Lancet 2004, 363(9407), 417-421.

14. Ironside, J. W.; Bishop, M. T.; Connolly, K.; Hegazy, D.; Lowrie, S.; Le Grice, M.; Ritchie, D. L.; McCardle, L. M.; Hilton, D. A. Variant Creutzfeldt-Jakob Disease: Prion Protein Genotype Analysis of Positive Appendix Tissue Samples from a Retrospective Prevalence Study. BMJ 2006, 332(7551), 1186-1188.

15. Peden, A. H.; Head, M. W.; Diane, L. R.; Jeanne, E. B.; James, W. I Preclinical vCJD after Blood Transfusion in a PRNP Codon 129 Heterozygous Patient. Lancet 2004, 364(9433), 527-529.

16. Hilton, D. A.; Ghani, A. C.; Conyers, L.; Edwards, P.; McCardle, L.; Ritchie, D.; Penney, M.; Hegazy, D.; Ironside, J. W. Prevalence of Lymphoreticular Prion Protein Accumulation in UK Tissue Samples. J. Pathol. 2004, 203(3), 733-739.

17. Qin, K.; Yang, Y.; Mastrangelo, P.; Westaway, D. Mapping Cu(II) Binding Sites in Prion Proteins by Diethyl Pyrocarbonate Modification and Matrix-Assisted Laser Desorption Ionization-Time of Flight (MALDI-TOF) Mass Spectrometric Footprinting. J. Biol. Chem. 2002, 277(3), 1981-1990.

18. Requena, J. R.; Groth, D.; Legname, G.; Stadtman, E. R.; Prusiner, S. B.; Levine, R. L. Copper-Catalyzed Oxidation of the Recombinant SHa(29231) Prion Protein. Proc. Natl. Acad. Sci. U.S.A. 2001, 98(13), 7170-7175.

19. Whittal, R. M.; Ball, H. L.; Cohen, F. E.; Burlingame, A. L. Prusiner, S. B. Baldwin, M. A. Copper Binding to Octarepeat Peptides of the Prion Protein Monitored by Mass Spectrometry. Protein Sci. 2000, 9, 2, 332-343.

20. Onisko, B.; Dynin, I.; Requena, J. R.; Silva, C. J.; Erickson, M.; Carter, J. M. Mass Spectrometric Detection of Attomole Amounts of the Prion Protein by nanoLC/MS/MS. J. Am. Soc. Mass Spectrom. 2007, 18(6), 1070-1079.

21. Back, J. W.; Sanz, M.A.; De Jong, L.; De Koning, L. J.; Nijtmans, L. G.; De Koster, C. G.; Grivell, L. A.; Van Der Spek, H.; Muijsers, A. O. A Structure for the Yeast Prohibition Complex: Structure Prediction and Evidence from Chemical Crosslinking and Mass Spectrometry. Protein Sci. 2002, 11(10), 2471-2478.

22. Pushie, M. J.; Ross, A. R.; Vogel, H. J. Mass Spectrometric Determination of the Coordination Geometry of Potential Copper(II) Surrogates for the 
Mammalian Prion Protein Octarepeat Region. Anal. Chem. 2007, 79(15), 5659-5667.

23. Maras, B.; Barra, D.; Schinina, M. E.; Cardone, F.; Pocchiari, M. Prion (PrPres) Allotypes Profiling: New Perspectives from Mass Spectrometry. Eur. J. Mass Spectrom. 2004, 10, 371-382.

24. Principe, S.; Maras, B.; Schinina, M. E.; Pocchiari, M.; Cardone, F. Unraveling the Details of Prion (con)Formation(s): Recent Advances by Mass Spectrometry. Curr. Opin. Drug Discov. Devel. 2008, 11(5), 697-707.

25. Wyttenbach, T.; Kemper, P. R.; Bowers, M. T. Design of a New Electrospray Ion Mobility Mass Spectrometer. Int. J. Mass Spectrom. 2001, 212(1/3), 13-23.

26. Thalassinos, K.; Grabenauer, M.; Slade, S. E. Hilton, G. R. Bowers, M. T.; Scrivens, J. H. Characterization of Phosphorylated Peptides Using Traveling Wave-Based and Drift Cell Ion Mobility Mass Spectrometry. Anal. Chem. 2009, 81(1), 248-254.

27. Mehlhorn, I.; Groth, D.; Stockel, J.; Moffat, B.; Reilly, D.; Yansura, D.; Willett, W. S.; Baldwin, M.; Fletterick, R.; Cohen, F. E.; Vandlen, R. Henner, D.; Prusiner, S. B. High-Level Expression and Characterization of a Purified 142-Residue Polypeptide of the Prion Protein. Biochemistry 1996, 35(17), 5528-5537.

28. Sanghera, N.; Pinheiro, T. J. T. Binding of Prion Protein to Lipid Membranes and Implications for Irion Conversion. J. Mol. Biol. 2002, 315(5), 1241-1256.

29. Martins, S. M.; Frosoni, D. J.; Martinez, A. M.; De Felice, F. G.; Ferreira, S. T. Formation of Soluble Oligomers and Amyloid Fibrils with Physical Properties of the Scrapie Isoform of the Prion Protein from the CTerminal Domain of Recombinant Murine Prion Protein mPrP-(121231). J. Biol. Chem. 2006, 281(36), 26121-26128.

30. Goormaghtigh, E.; Cabiaux, V.; Ruysschaert, J. M. Secondary Structure and Dosage of Soluble and Membrane Proteins by Attenuated Total Reflection Fourier-Transform Infrared Spectroscopy on Hydrated Films. Eur. J. Biochem. 1990, 193(2), 409-420.

31. Gidden, J.; Ferzoco, A.; Baker, E. S.; Bowers, M. T. J. Am. Chem. Soc. 2004, $126,15132$.

32. Wildgoose, J. L; Giles, K.; Pringle, S. D.; Koeniger, S. J.; Valentine, R. H.; Bateman, R. H.; Clemmer, D.E. Proceedings of the 54th ASMS Conference on Mass Spectrometry and Allied Topics; Seattle, January, 2005.

33. Scarff, C. A; Thalassinos, K.; Hilton, G. R.; Scrivens, J. H. Traveling Wave Ion Mobility Mass Spectrometry Studies of Protein Structure: Biological Significance and Comparison with X-ray Crystallography and Nuclear Magnetic Resonance Spectroscopy Measurements. Rapid Commun. Mass Spectrom. 2008, 22(20), 3297-3304.

34. Ruotolo, B. T.; Giles, K.; Campuzano, I.; Sandercock, A. M.; Bateman, R. H.; Robinson, C. V. Evidence for Macromolecular Protein Rings in the Absence of Bulk Water. Science 2005, 310(5754), 1658-1661.

35. Scrivens J. H.; Thalassinos, K.; Hilton, G. R., Slade, S. E.; Pinheiro, T. J. T.; Bateman, R. H.; Bowers, M. T. Proceedings of the 55th ASMS Conference on Mass Spectrometry and Allied Topics; Indianapolis, June, 2006.
36. Ruotolo, B. T.; Benesch, J. L.; Sandercock, A. M.; Hyung, S. J.; Robinson, C. V. Ion Mobility-Mass Spectrometry Analysis of Large Protein Complexes. Nat. Protoc. 2008, 3(7), 1139-1152.

37. Clemmer, D. E. http://www.indiana.edu/ clemmer/.

38. Mesleh, M. F.; Hunter, J. M.; Shvartsburg, A. A.; Schatz, G. C.; Jarrold M. F. Structural Information from Ion Mobility Measurements: Effects of the Long-Range Potential. J. Phys. Chem. 1996, 100(40), 16082-16086.

39. Caughey, B.; Race, R. E.; Ernst, D.; Buchmeier, M. J.; Chesebro B. Prion Protein Biosynthesis in Scrapie-Infected and Uninfected Neuroblastoma Cells. J. Virol. 1989, 63(1), 175-181.

40. Borchelt, D. R.; Scott, M.; Taraboulos, A.; Stahl, N.; Prusiner, S. B. Scrapie and Cellular Prion Proteins Differ in Their Kinetics of Synthesis and Topology in Cultured Cells. J. Cell. Biol. 1990, 110(3), 743-752.

41. Caughey, B.; Raymond, G. J. The Scrapie-Associated Form of PrP Is Made from a Cell Surface Precursor That Is Both Protease- and Phospholipase-Sensitive. J. Biol. Chem. 1991, 266(27), 18217-18223.

42. Yedidia, Y.; Horonchik, L.; Tzaban, S.; Yanai, A.; Taraboulos, A Proteasomes and Ubiquitin Are Involved in the Turnover of the Wild-Type Prion Protein. EMBO J. 2001, 20(19), 5383-5391.

43. Hosszu, L. L.; Trevitt, C. R.; Jones, S.; Batchelor, M.; Scott, D. J.; Jackson, G. S.; Collinge, J.; Waltho, J. P.; Clarke, A. R. Conformational Properties of \{beta\}-PrP. J. Biol. Chem. 2009, 284(33), 21981-21990.

44. Li, J.; Browning, S.; Mahal, S. P.; Oelschlegel, A. M; Weissmann, C. Darwinian Evolution of Prions in Cell Culture. Science 2009, 869-872.

45. Gambetti, P.; Dong, Z:; Yuan, J.; Xiao, X.; Zheng, M.; Alshekhlee, A. Castellani, R.; Cohen, M.; Barria, M. A.; Gonzalez-Romero, D.; Belay, E. D.; Schonberger, L. B.; Marder, K.; Harris, C.; Burke, J. R.; Montine, T.; Wisniewski, T.; Dickson, D. W.; Soto, C.; Hulette, C. M.; Mastrianni, J. A.; Kong, Q.; Zou, W. Q. A Novel Human Disease with Abnormal Prion Protein Sensitive to Protease. Ann. Neurol. 2008, 63(6), 697-708.

46. Castilla, J.; Saa, P.; Hetz, C.; Soto, C. In Vitro Generation of Infectious Scrapie Prions. Cell 2005, 121(2), 195-206.

47. Grabenauer, M.; Sanghera, N.; Pinheiro, T. J.; Scrivens, J. H.; Bowers, M. T. Conformational Stability of Syrian Hamster Prion Protein PrP(90231). 2009, unpublished, (submitted).

48. Badman, E. R.; Myung, S.; Clemmer, D. E. Evidence for Unfolding and Refolding of Gas-Phase Cytochrome $c$ Ions in a Paul Trap. J. Am. Soc. Mass Spectrom. 2005, 16(9), 1493-1497.

49. Wyttenbach, T.; Grabenauer, M.; Thalassinos, K.; Scrivens, J. H.; Bowers, M. T. The Effect of Calcium Ions and Peptide Ligands on the Stability of the Calmodulin Dumbbell Structure. 2009, unpublished, (submitted).

50. Caughey, B. Cellular Metabolism of Normal and Scrapie-Associated Forms of PrP. Semin. Virol. 1991, 2, 189-196.

51. Weissmann, C. Molecular Genetics of Transmissible Spongiform Encephalopathies. J. Biol. Chem. 1999, 274(1), 3-6. 